\title{
Identification of Children at Risk for Reading Disabilities in Elementary Schools in Oman: The Role of Phoneme Segmentation and Phoneme Blending in Learning Arabic
}

\author{
Mahmoud Mohamed Emam, Raya Al-Mandhari, Sharifa Khaled Al-Said, Jokha Al-Kalbani, Mariam \\ Al-Lemky, and Saleh Al-Mekmary
}

\begin{abstract}
Reading skills have begun to be strongly considered by researchers and practitioners for the identification of students who have or at risk for reading disabilities (RDs). The current study investigated role of phoneme segmentation and phoneme blending in identifying children at risk for RDs. 240 students from the second and fourth grade and who were either referred for the learning disabilities unit or who were normally achieving responded to tests on phoneme segmentation (PS) and phoneme blending (PB). A three way MANOVA showed that female students attained higher scores on PS and PB than did female students; fourth grade students attained higher scores on PS but not on PB than did second grade students; and finally normally achieving students attained higher scores on PS and PB than did students referred for RDs. No interaction effects of the three variables were significant. Results are discussed in relation to the component model of reading.
\end{abstract}

Index Terms-Reading disabilities, component model of reading, phonological awareness.

\section{INTRODUCTION}

Reading Disabilities (RDs) refer to a number of difficulties in reading related-processes which pupils experience due to neurological related causes, atypical brain functioning as well as atypical informal processing. Known as the most common learning disability (LD), RDs have severe academic social and emotional consequences on pupils. In western contexts, epidemiological studies show that the number of pupils with LDs in schools ranges from $15 \%$ to $30 \%$ of the pupils' population. Of all pupils with LDs $70 \%-80 \%$ have deficits in reading [1]-[3]. In general, school practices for pupils with RDs have been informed by two competing models, namely, the discrepancy and the Response to Intervention (RTI) the first cycle of basic education schools in Oman (grades 1-4) and the fact that identification and intervention practices have been inadequately shaped by mere labeling as guided by the discrepancy model, the search for new paradigms has become essential. Recently the author attained a fund for conducting strategic research to establish an optimal framework for teaching pupils with RDs in Oman. The framework includes identification of RDs based on a comprehensive neuropsychological perspective in addition to

Manuscript received June 1, 2014; revised August 8, 2014. This work was supported fully by His Majesty's Research Trust Fund (HMRTF) at Sultan Qaboos University under grant No. (SR/EDU/PSYC/12/01).

Mahmoud Mohamed Emam is with the Sultan Qaboos University, Oman (e-mail: memam@squ.edu.om). setting up a model of best practices informed by the RTI multi-tiered instructional strategy for teaching pupils with RDs in schools, combining features from the component model of reading in the Arabic language. In this paper the authors focus the component model of reading which focuses on the essential reading skills of the Arabic language. We test one main element of the model, namely phonological awareness (PA) by comparing between the performances of students referred for RDs and normally achieving (NA) students.

\section{Current Study}

In Arabic, the end goal is for readers to read unvoweled text fluently and with comprehension. In this review paper the author summarize the major discussions in the scholarly literature on what variables are most critical to attaining this goal. Many studies across the literature identify three variables as critical to learning to read in Arabic: phonological awareness, morphological knowledge and sentence context. Fig. 1 shows the three components.

Phonological awareness is understood as a person's awareness of the sound structure of spoken words. It has proven to be a consistent predictor of later reading ability in children in many languages [10]. In Arabic phonological awareness is also key variable in reading acquisition and a critical skill that children must master to be readers of both vocalized and unvocalized text.

Literature citing evidence on the role of phonological awareness in learning to read in Arabic is discussed below. Both Abdel Bari [4] and Halebah [5] state that phonological awareness is one of the important introductory steps to reading in general and reading in Arabic specifically. Since Arabic is a phonetically written language being able to pronounce letter sounds is one of the strategies that helps new readers decode the words they do not recognize by sight.

This phonetic approach (tariqa al sautiya) is considered recent in terms of teaching strategies, when compared to the "spelling way" (tariqa al hijayia) which it was widely used in the 19th century and is still used [4]. Abu-Rabia, Share and Mansour [6], in a 2003 study investigating word identification in Arabic and basic cognitive processes in reading-disabled (RD) and normal readers of the same age and younger normal readers who were the same level as the $\mathrm{RD}$ readers, stated that:

Phonological decoding ability is essential in the process of reading acquisition [7], [8]. It is well established in the literature that measuring the pseudoword reading is the benchmark test of children's phonological decoding skill [9]. 
Many studies have been conducted using pseudowords as their phonological decoding measure among normal readers and reading disabled (RD) children...The difficulty of these $\mathrm{RD}$ children in reading pseudowords seems to be the result of deficiencies in their basic phonological processing (emphasis added) [6].

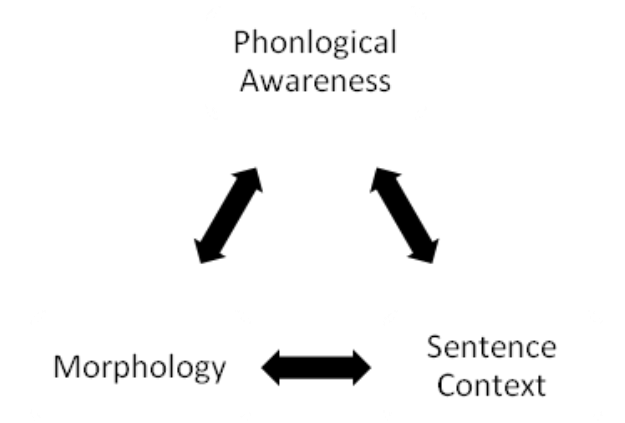

Fig. 1. The three main components of the Arabic language

In their discussion of the results of this 2003 study Abu Rabia, Share and Mansour remark, "In sum, the reading-disabled in Arabic generally showed similar characteristics to those reported in the literature: poor phonological processing, poor working memory skills, and poor syntactic skills. However, they tended to show strong visual-orthographic patterns of reading from an early age. Phonology seems to be extremely powerful, followed by morphology andvisual memory. Syntax and working memory are also important, although they show less consistency [6].

In 2011, Taibah and Haynes [10] carried out a cross sectional study on the contributions of phonological processing-defined as phonological awareness (the capacity to reflect on the sound structure of spoken words), rapid naming (RAN) (capacity to retrieve phonological codes stored in memory) and phonological memory (processing resource of limited capacity involved in the preservation of information) - to decoding and fluency skills in Arabic among 237 Arabic speaking children in Grades K-3 in Saudi Arabia [10]. Results showed that at each grade phonological processing skills correlated significantly with all reading skills at a range from moderate to high. Indeed, the study showed that readers lacking automaticity relied more on phonological awareness than rapid naming capacity or phonological memory. The predictive power of rapid naming increased in grades 2 and 3 and the predictive power of phonological awareness decreased in grade 2 although was still more powerful than rapid naming. "These findings are consistent with the view that fluency in the beginning grade levels relies on accuracy of decoding - a skill highly dependent on phonological awareness. In parallel, as children progress to second and third grades and develop decoding that is more automatic, the predictive power of RAN increases" [10].

From a 2012 study, Abu-Rabia [11] posited that the phonological stage in reading is continuous even in proficient adult readers. A study of 59 skilled native Arabic readers found that: roots facilitate reading accuracy in reading morphological complex words, with and without short vowelization; short vowelization aids the reading accuracy of morphological complex word; and, short vowelization also aids in the accurate reading of morphologically complex words in context compared to reading them without short vowelization [11]. The significant effect of vowels on reading morphologically complex words among highly proficient adult readers means that the phonological stage in reading Arabic is a continuous stage that accompanies even highly skilled adult Arabic readers all their lives. Such a finding is divergent from results obtained from other orthographies; that phonology is an initial stage in reading and writing, and that for readers to become fluent, they should rely on their automatic lexical-visual-recognition of words, based on their rich orthographic mental lexicon. [11] These findings demonstrate how critical it is for pupils to learn Phonological awareness skills in the early years of their reading instruction.

Assessment of phonological awareness can be carried out using the same types of tests that were applied in the English language. These include: Blending, Segmentation, phoneme manipulation, sound identification. The processes can be examined through tasks which involve words and non-words. In the current study we explored the role of phoneme segmentation (PS) and phoneme Blending (PB) in identifying children at risk for reading disabilities in Oman. Phoneme segmentation refers to the student's ability to break words down into individual sounds. Phoneme Blending refers to the ability to combine individual sounds to make new entities of new structures. Additionally we investigated the effect of gender (Male vs. female), grade level (second vs. fourth grade), condition (RDs vs. NA) on the performance on students on phonological awareness tests. The questions of the study are as follows:

1) Within grades two and four will PS and PB performance differ as a result of gender, condition, and grade level?

2) Within grades two and four will PS and PB performance differ as a result of the interaction between gender and grade level, gender and condition, grade level and condition, and finally between gender, grade level and condition?

\section{METHOD}

\section{A. Participants}

Participants included 240 students from grades two and four whose native language is Arabic (see Table I). The data were collected from different schools representing the 11 demographic areas in Oman: North, Middle, Southeast, and Southwest. Arabic language instruction started in grade 1 and placed heavy emphasis on phonics and vocabulary instruction. Across the different schools, curricular goals and objectives, materials, and reading instruction methods were similar. All classes were taught in Arabic. Students from both grades were chosen randomly for both conditions (NA and $\mathrm{RD}$ ) and consent forms were sent to parents seeking their agreement of participation. The students ranged in age from 7.33 to 9.25 years and came from Arabic ethnic backgrounds and from families in which both parents spoke Arabic at home. None had sensory problems that interfered with learning. Children of expats were excluded from the study 
and only Omani participants were included

\section{B. Materials and Instruments}

\section{1) Phonological awareness}

Two subtests were developed to measure PA skills, the phoneme segmentation (PS) and phoneme blending (PB) in words. The PS subtest contained a list of 20 items of increasing difficulty. The segmentation became more difficult as participants were required to drop out increasingly smaller segments of greater phonological complexity. Items progressed in difficulty. For the practice items, we added two more trials so that children could comprehend the instructions and task requirements. The Cronbach alpha was (0.96). for the second grade test and (0.92) for the fourth grade test. The items in the PB subtest were ordered by level of difficulty, according to word frequency, and following the same scheme employed for segmentation, progressing from syllables to phonemes. The correct answers represented real words in order to make scoring easier and to make the task more comprehensible for students. The test contained 20 items. The practice items consisted of three practice words to ensure that children comprehended the required task. Cronbach's alpha for the second grade two test items was (0.96) and for the fourth test items was also (0.96).

TABLE I: OVERVIEW OF THE PARTICIPANTS

\begin{tabular}{llcccc}
\hline \hline Condition & Gender & Grade 2 & Grade 4 & \multicolumn{2}{c}{ Total } \\
\hline \multirow{2}{*}{ ARDs } & Male & 30 & 30 & 60 & \multirow{2}{*}{120} \\
& Female & 30 & 30 & 60 & \\
NA & Male & 30 & 30 & 60 & 120 \\
Total & Female & 30 & 30 & 60 & 240 \\
\hline \hline \multicolumn{2}{c}{ Note: NA= Normally } & Achieving & pupils; & RDs $=$ & Reading \\
Disabilities. & & & & &
\end{tabular}

\section{RESULtS}

A three way MANOVA was conducted to examine the differences and variations in the measured phonological awareness skills, PS and PB, and the effects of condition (RDs vs. NA), gender (males vs. females), and Grade level (grade two vs. grade four) on students' reading skills. In addition we examined the effects of the interaction between the three conditions. Gender, condition and grade were all entered into the MANOVA independent variable and the PS and PB as dependent variables. Table II shows the means and standard deviations of the students according to gender, grade level and condition.

As shown in Table III the main effect of gender was significant, Wilks' $\lambda=.97, F_{(2,231)}=3.26, p<.040, \eta p^{2}=.03$. Compared to males, females attained higher scores on PS $\left(F_{11}\right.$ $\left.\left.{ }_{232}\right)=5.79, p=.01, \eta p^{2}=.02\right), \mathrm{PB}\left(F_{(1,232)}=4.60, p=.03, \eta p^{2}\right.$ $=.02$ ). Grade (grade two vs. grade 4) was also significant, Wilks' $\lambda=.94, F_{(2,231)}=6.85, p<.001, \eta p^{2}=.06$. Compared to second grade students, fourth grade students attained higher scores on PS $\left(F_{(1,232)}=10.99, p=.001, \eta p^{2}=.05\right)$. However there was no difference between both on PB $\left(F_{(1,232)}\right.$ $\left.=.46, p=.500, \eta p^{2}=.00\right)$. Condition (RDs vs. NA) was also significant, Wilks' $\lambda=.50, F_{(2,231)}=114.20, p<.001$, $\eta p^{2}=.50$. Compared to students referred for RDs, NA students attained higher scores on PS $\left(F_{(1,232)}=184.38, p=\right.$ $\left.001, \eta p^{2}=.44\right), \operatorname{PB}\left(F_{(1,232)}=183.48, p=.001, \eta p^{2}=.44\right)$.

TABLE II: MEANS AND STANDARD DEVIATIONS OF THE PARTICIPANTS ON THE PS AND PB TESTS

\begin{tabular}{|c|c|c|c|c|c|c|c|}
\hline \multirow[t]{2}{*}{ Gender } & \multirow{2}{*}{ Grade } & \multirow{2}{*}{$\begin{array}{l}\text { Conditi } \\
\text { on }\end{array}$} & \multirow{2}{*}{$N$} & \multicolumn{2}{|c|}{ PS } & \multicolumn{2}{|c|}{$\mathrm{PB}$} \\
\hline & & & & $M$ & $S D$ & $M$ & $S D$ \\
\hline \multirow[t]{9}{*}{ Male } & \multirow[t]{3}{*}{2} & RDs & 30 & 17.17 & 24.48 & 34.00 & 31.99 \\
\hline & & NA & 30 & 62.50 & 37.78 & 84.17 & 28.38 \\
\hline & & Total & 60 & 39.83 & 38.97 & 59.08 & 39.22 \\
\hline & \multirow[t]{3}{*}{4} & RDs & 30 & 30.83 & 24.00 & 36.50 & 30.85 \\
\hline & & NA & 30 & 70.00 & 34.34 & 72.17 & 29.56 \\
\hline & & Total & 60 & 50.42 & 35.39 & 54.33 & 34.94 \\
\hline & \multirow[t]{3}{*}{ Total } & RDs & 60 & 24.00 & 25.01 & 35.25 & 31.18 \\
\hline & & NA & 60 & 66.25 & 35.99 & 78.17 & 29.36 \\
\hline & & Total & 120 & 45.13 & 37.45 & 56.71 & 37.06 \\
\hline \multirow[t]{9}{*}{ Female } & \multirow[t]{3}{*}{2} & RDs & 30 & 14.33 & 22.04 & 30.83 & 33.01 \\
\hline & & NA & 30 & 79.83 & 26.89 & 88.17 & 15.34 \\
\hline & & Total & 60 & 47.08 & 41.05 & 59.50 & 38.56 \\
\hline & \multirow[t]{3}{*}{4} & RDs & 30 & 36.17 & 28.91 & 45.33 & 28.68 \\
\hline & & NA & 30 & 85.50 & 25.27 & 92.67 & 11.50 \\
\hline & & Total & 60 & 60.83 & 36.65 & 69.00 & 32.23 \\
\hline & \multirow[t]{3}{*}{ Total } & RDs & 60 & 25.25 & 27.76 & 38.08 & 31.52 \\
\hline & & NA & 60 & 82.67 & 26.03 & 90.42 & 13.63 \\
\hline & & Total & 120 & 53.96 & 39.36 & 64.25 & 35.71 \\
\hline \multirow[t]{9}{*}{ Total } & \multirow[t]{3}{*}{2} & RDs & 60 & 15.75 & 23.14 & 32.42 & 32.27 \\
\hline & & NA & 60 & 71.17 & 33.67 & 86.17 & 22.71 \\
\hline & & Total & 120 & 43.46 & 40.02 & 59.29 & 38.73 \\
\hline & \multirow[t]{3}{*}{4} & RDs & 60 & 33.50 & 26.48 & 40.92 & 29.87 \\
\hline & & NA & 60 & 77.75 & 30.90 & 82.42 & 24.52 \\
\hline & & Total & 120 & 55.63 & 36.26 & 61.67 & 34.27 \\
\hline & \multirow[t]{3}{*}{ Total } & RDs & 120 & 24.63 & 26.32 & 36.67 & 31.25 \\
\hline & & NA & 120 & 74.46 & 32.34 & 84.29 & 23.61 \\
\hline & & Total & 240 & 49.54 & 38.59 & 60.48 & 36.51 \\
\hline
\end{tabular}

Note: NA= Normally Achieving pupils; RDs= Reading Disabilities; $\mathrm{N}=$ Number of Participants; $\mathrm{M}=$ Mean; $\mathrm{SD}=$ Standard Deviations.

TABLE III: WILKS'S LAMBDA SIGNIFICANCE FOR THE THREE WAY MANOVA

\begin{tabular}{lcccccc}
\hline \hline & & & & & & \\
Effect & Value & $F$ & $d f$ & & Sig. & $\eta p^{2}$ \\
\hline Gen. (A) & .97 & 3.26 & 2 & 231 & .040 & .03 \\
Gr (B) & .94 & 6.85 & 2 & 231 & .001 & .06 \\
Con (C) & .50 & 114.2 & 2 & 231 & .001 & .50 \\
A $*$ B & .98 & 2.54 & 2 & 231 & .081 & .02 \\
A * C & .98 & 2.13 & 2 & 231 & .121 & .02 \\
B * C & .99 & 1.68 & 2 & 231 & .188 & .01 \\
A * B $*$ C & .99 & .65 & 2 & 231 & .523 & .01 \\
\hline \hline
\end{tabular}

Note: Gen(A), Gender, Gr(B)., Grade, Cond (C), Condition.

For the interaction between gender and grade level, gender and condition, and between the three variables the results revealed no significant effects. Table IV shows the performance of the participants according to gender, grade level and condition.

\section{DISCUSSION}

This cross-sectional study examined relationships between the PA of grade two and grade four students in Oman. The aim was to examine whether PA can be used to differentiate between students who are at risk for RDs as opposed to NA students. We tested PA through the use of subtests of two core skills, namely PS and PB. The results revealed that in 
grades two and four PA as measured by PS and PA differed between the two grades.

TABLE IV: RESULTS OF THE THREE WAY MANOVA

\begin{tabular}{lccccccc}
\hline \hline Source & Varia & SS & $d f$ & MS & $F$ & $p$ & $\eta p^{2}$ \\
Gen & PS & 4681.67 & 1 & 4681.6 & 5.79 & .017 & .02 \\
(A) & PB & 3412.60 & 1 & 3412.6 & 4.60 & .033 & .02 \\
\hline Gr & PS & 8881.67 & 1 & 8881.6 & 10.9 & .001 & .05 \\
(B) & PB & 338.44 & 1 & 338.4 & .46 & .500 & .00 \\
\hline Cond & PS & 149001.67 & 1 & 149001.6 & 184.3 & .001 & .44 \\
(C) & PB & 136088.44 & 1 & 136088.4 & 183.4 & .001 & .44 \\
\hline & PS & 187488.33 & 232 & 808.14 & & & \\
Error & PB & 172077.50 & 232 & 741.71 & & & \\
\hline \hline
\end{tabular}

Note: $\mathrm{SS}=$ Sum of Squares, MS=Mean squares, $\mathrm{PS}=$ phoneme segmentation, $\mathrm{PB}=$ phoneme blending, $\mathrm{Gen}(\mathrm{A})$, Gender, $\mathrm{Gr}(\mathrm{B})$., Grade, Cond $(\mathrm{C})$, Condition

There were significant differences in PS and PA as a result of gender, grade level, and condition. However, there were no significant differences in PB as a result of grade level. These findings are consistent with other studies of Arabic [10], [12]. The results also reflect similar finding on English language [13], [14].

The PA measures in the current study relied on two key skills, namely PS and PB. The measures included material that was gradually increasing in complexity from phoneme level size, to syllable, to word employed stimuli of gradually decreasing. The performance of the students from both grades differed in PS and not in PB. This can be attributed back to the fact that in PS it is easier to rely on syllables rather than Phoneme or word. Previous research has shown that awareness of larger phonological units and not just phoneme level awareness is linked with early reading development [15]. In PA, however, the students are required to start from phoneme level in most cases which makes it more difficult for them to show mastery in their performance.

Researchers have suggested that reading and PA skills develop in a parallel an interaction manner [16]. This means that vocabulary growth and repeated exposure to the statistical regularities present in the spoken language may form the basis for learning about phonological characteristics of language, but access to individual phonemes does not develop prior to the formal instruction of alphabetic reading. This is because through exposure to orthographic patterns and their corresponding sounds students develop their ability to isolate phonemes in the speech production and recognize that letters or letter combinations represent phonemic elements of speech [9], [11]. The study's finding of the differences in PS therefore supports to this argument, although not totally since there were no differences in PB between grade two and grade four students. Given that the previous argument reflects that PA and reading skills develop hand in hand there should have been similar differences in PB. The PS measure in the current study was a developmentally sensitive measure for the two grades assessed and that PA can be used to differentiate between NA students and student at risk for RDs.

The effect of gender on PA measures is an interesting finding in the study. Our results showed that girls performed better on the PA measures than did boys. The issue of gender differences in problematic in literacy research in general [17]. According to Berninger and her colleagues males were Males were consistently more impaired than females in orthographic skills. This may be reflected in part in our findings which showed s supremacy for girls on the PA measures. The effect of condition was also significant as NA students from both grades performed better on the PA measures than did the students referred for RDs. This finding replicates previous research findings both on Arabic as well as on English orthography [18]. The interaction between variables of gender and grade level, gender and condition, grade level and condition as well as the three variables together was not significant. This reflects that PA is better examined independently when any intervention should be planned for students at risk for RDs.

\section{CONCLUSION}

We explored the differences in PA between second and fourth grade students; and explored the effect of gender, grade level and condition on PA measures. This current study is not without limitations. We compared cross-sectional data in order to make developmental inferences about the variations in PA measures and the effect of gender, grade level and condition variables as well as the interaction of these variables together. While PA sub-tests developed for these analyses, PS and PB, appear to be developmentally sensitive and informative; a longitudinal study, however, is needed in order to map individual children's actual growth trajectories for these two as well as other PA and reading abilities. Tracking the same students over time and extending the span of study to the earlier as well as later grade school years will allow researchers to draw more definitive conclusions about PA in relation to other variables as well as the literacy outcomes that are of interest.

\section{ACKNOWLEDGMENT}

This work was funded by the His Majesty's Research Trust Fund (HMRTF) at Sultan Qaboos University under grant No. (SR/EDU/PSYC/12/01). The authors, therefore, acknowledge with thanks HMRTF technical and financial support.

\section{REFERENCES}

[1] C. Christo, J. Davis, and S. Brock, Identifying, Assessing, and Treating Dyslexia at School, Springer, 2009.

[2] E. Veuillet, A. Magnan, J. Ecalle, H. T. Van, and L. Collet, "Auditory processing disorder in children with reading disabilities: effect of audiovisual training," Brain, vol. 130, pp. 2915-2928, 2007.

[3] C. Silver, R. Ruff, G. Iverson. J. Barth, D. Broshek, S. Bush, S. Koffle, and C. Reynolds, "Learning disabilities: the need for neuropsychological evaluation," Archives of Clinical Neuropsychology, vol. 23, pp. 217-219, 2007.

[4] M. S. A. Bari. (2011). The Holistic Approach to Reading. from Arab Bureau of Education for the Gulf States. [Online]. Available: http://www.abegs.org/Aportal/Post/Show?id=10871\&forumid=23

[5] M. Halebah. (2013). Methods of Teaching Reading for Beginners. from Umm Al-Qura University. [Online]. Available: http://uqu.edu.sa/page/ar/121401

[6] S. A. Rabia, D. Share, and M. S. Mansour, "Word recognition and basic cognitive processes among reading-disabled and normal readers in 
Arabic," Reading and Writing: An Interdisciplinary Journal, vol. 16 pp. 423-442, 2003.

[7] S. A. Rabia and L. S. Siegel, "Different orthographies, different context effects: The effects of Arabic sentence context in skilled and poor readers," Reading Psychology: An International Quarterly, vol. 16, pp. $1-19,1995$.

[8] A. F. Jorm, "The cognitive and neurological basis of developmental dyslexia: a theoretical framework and review," Cognition, vol. 7, pp. 19-33, 1979.

[9] S. A. Rabia, "Reading in Arabic orthography: the effect of vowels and context on reading accuracy of poor and skilled native Arabic readers," Reading and Writing: an Interdisciplinary Journal, vol. 9, pp. 65-78, 1997.

[10] N. J. Taibah and C. W. Haynes, "Contributions of phonological processing skills to reading skills in Arabic speaking children," Reading and Writing, vol. 24, pp. 1019-1042, 2011.

[11] S. A. Rabia, "The role of morphology and short Vowelization in reading morphological complex words in Arabic: evidence for the domination of the morpheme/root-based theory in reading Arabic," Creative Education, vol. 3, pp. 486-494, 2012.

[12] G. Elbeheri and J. Everatt, "Literacy ability and phonological processing skills amongst dyslexic and non-dyslexic speakers of Arabic," Reading and Writing: an Interdisciplinary Journal, vol. 20, pp. 273-294, 2007.

[13] J. K. Torgesen, R. K. Wagner, C. A. Rashotte, S. Burgess, and S. Hecht, "Contributions of phonological awareness and rapid automatic naming ability to the growth of word-reading skills in second- to fifth-grade children," Scientific Studies of Reading, vol. 1, pp. 161-185, 1997.

[14] R. K. Wagner, J. K. Torgesen, and C. Rashotte, "Development of reading-related phonological processing abilities: New evidence of bidirectional causality from latent variable longitudinal study," Developmental Psychology, vol. 30, pp. 73-87, 1994.

[15] S. A. Rabia, "The role of vowels in reading Semitic scripts: data from Arabic and Hebrew," Reading and Writing: an Interdisciplinary Journal, vol. 14, pp. 39-59, 2001.

[16] J. C. Ziegler and U. Goswami, "Reading acquisition, developmental dyslexia, and skilled reading across languages: a psycholinguistic grain size theory," Psychological Bulletin, vol. 131, pp. 3-29, 2005.

[17] V. W. Berninger, K. H. Nielsen, R. D. Abbott, E. Wijsman, and W. Raskind, "Gender differences in severity of writing and reading disabilities," Journal of School Psychology, vol. 46, pp. 151-172, 2008

[18] E. S. Haddad and E. Geva, "Morphological awareness, phonological awareness, and reading in English-Arabic bilingual children," Reading and Writing: an Interdisciplinary Journal, vol. 21, pp. 481-504, 2008

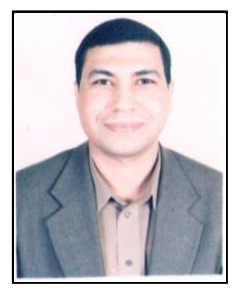

Mahmoud Mohamed Emam is an assistant professor of special education. He holds a $\mathrm{PhD}$ in children with special educational needs studies from the University of Manchester. He attained two Fulbright scholarships during which he worked at the University of Kansas in 2004, and University of Florida, Gainesville. He also received an Erasmus Mundus Scholarship in lifelong learning: policy and management that is focused on underachievers in community schools in Egypt.

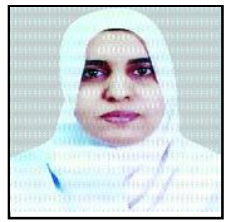

Raya Al-Mandhari is an assistant professor of Arabic Instruction at Curriculum and Instruction Department, Sultan Qaboos University. Dr. Raya received her $\mathrm{PhD}$ from the University of Southern Queensland in Australia. Her work is focused on Arabic teaching methods for children with without learning difficulties.

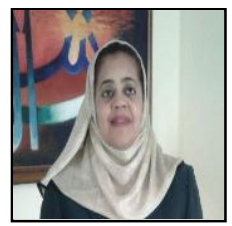

Shariffa Al-Said is an educational expert in the Ministry of Education in the Sultanate of Oman. She holds a master (M.S.Ed) from Connecticut State University, USA, and a master (M.Ed) from Columbia University, and a $\mathrm{PhD}$ from Columbia University. She conducts action research and is dedicated to improving educational services to students with special education needs in Oman.

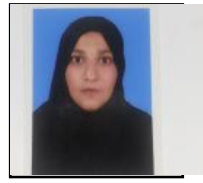

JoKha Al-Kalbani is a teacher supervisor in the area of students with learning disabilities in Oman. She holds a master in special education with a focus on LD from King Saud University in Saudi Arabia. She has been interested in conducting a number of action research studies in the area of LD.

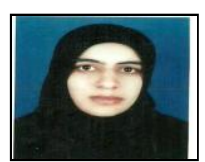

Mariam Al-Lemky is a teacher supervisor in the area of students with learning disabilities in Oman. She holds a master in special education with a focus on LD from Saint Joseph University in Lebanon. She has conducted a number of action research studies in the area of LD.

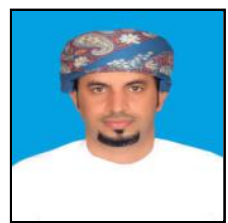

Saleh Al-Mekmary is teacher supervisor in the area of students with learning disabilities in Oman. He is a graduate of the teachers' college in Oman. $\mathrm{He}$ is interested in conducting action research in Oman schools in order to advance the field of special education in Oman. 